\title{
Cross-validation of the Beunen-Malina method to predict adult height
}

\author{
GASTON P. BEUNEN ${ }^{1}$, ROBERT M. MALINA ${ }^{2}$, DUARTE I. FREITAS ${ }^{3}$, \\ JOSÉ A. MAIA ${ }^{4}$, ALBRECHT L. CLAESSENS ${ }^{1}$, ELVIO R. GOUVEIA ${ }^{3}$ \& \\ JOHAN LEFEVRE ${ }^{1}$
}

${ }^{1}$ Department of Biomedical Kinesiology, Faculty of Kinesiology and Rehabilitation Sciences, KULeuven, Leuven, Belgium, ${ }^{2}$ Department of Kinesiology and Health Education, University of Texas at Austin, and Tarleton University, Stephenville, TX, USA, ${ }^{3}$ Department of Physical Education and Sports, University of Madeira, Autonomous Region of Madeira, Portugal, and ${ }^{4} F C I F I^{2}-D$, Faculty of Sport, University of Porto, Porto, Portugal

(Received 2 September 2009; accepted 29 September 2009)

\begin{abstract}
The purpose of this study was to cross-validate the Beunen-Malina method for non-invasive prediction of adult height. Three hundred and eight boys aged 13, 14, 15 and 16 years from the Madeira Growth Study were observed at annual intervals in 1996, 1997 and 1998 and re-measured 7-8 years later. Height, sitting height and the triceps and subscapular skinfolds were measured; skeletal age was assessed using the Tanner-Whitehouse 2 method. Adult height was measured and predicted using the Beunen-Malina method. Maturity groups were classified using relative skeletal age (skeletal age minus chronological age). Pearson correlations, mean differences and standard errors of estimate (SEE) were calculated. Age-specific correlations between predicted and measured adult height vary between 0.70 and 0.85 , while age-specific SEE varies between 3.3 and $4.7 \mathrm{~cm}$. The correlations and SEE are similar to those obtained in the development of the original Beunen-Malina method. The BeunenMalina method is a valid method to predict adult height in adolescent boys and can be used in European populations or populations from European ancestry. Percentage of predicted adult height is a non-invasive valid method to assess biological maturity.
\end{abstract}

Keywords: Biological maturation, non-invasive method, adolescence, prediction

\section{Introduction}

Biological maturity status is related to body size, physique, body composition, muscular strength and physical performance in the general population of children and adolescents and

Correspondence: Gaston Beunen, PhD, FACSM, Department of Biomedical Kinesiology, Faculty of Kinesiology \& Rehabilitation Sciences, KULeuven, Tervuursevest 101, B3001 Leuven, Belgium. E-mail: gaston.beunen@faber.kuleuven.be 
in young athletes in a variety of sports (Beunen and Malina 2008; Malina et al. 2004). The accurate estimation of biological maturity is thus of considerable interest. Several methods for estimating biological maturation have been in use since early last century including, sexual, skeletal, morphological and dental protocols (Malina et al. 2004; Beunen and Malina 2008). Skeletal maturation is generally accepted as the best single maturity indicator since it spans infancy through adolescence, but it requires a small radiation dose and as such it is perceived as invasive. Indicators of sexual maturity are limited to the pubertal years and are assessed on a crude ordinal scale. Estimates of dental maturity also require radiation and these are not highly associated with other indicators of biological maturity (Malina et al. 2004; Beunen and Malina 2008). Bayley (1962) and Roche et al. (1983) proposed percentage of adult stature as a valid indicator of morphological or somatic maturity because it reaches the same endpoint in all adults (100\%), and increases monotonically with age. Several techniques that provide accurate prediction of adult stature have been developed, but all require skeletal age as an important predictor in the regression equations (Bayley and Pinneau 1952; Roche et al. 1975; Tanner et al. 1983a,b, 2001). Non-invasive techniques to predict adult stature without the use of skeletal maturity have also been developed (Wainer et al. 1978; Roche et al. 1983; Khamis and Roche 1994; Beunen et al. 1997). Beunen et al. (1997) demonstrated that, in boys aged 13-16 years accurate predictions of adult stature can be obtained with chronological age, current stature, sitting height, subscapular skinfold and triceps skinfold as predictors. This method, called the Beunen-Malina method, has not been cross-validated in another sample. The purpose of the present study is to cross-validate the Beunen-Malina method for prediction of adult height in an independent sample of adolescent boys of European origin.

\section{Methods}

\section{Sample}

Subjects are from the Madeira Growth Study (Freitas et al. 2004), a mixed longitudinal study with five birth cohorts $(8,10,12,14$ and 16 years) observed at annual intervals in 1996, 1997 and 1998 and four overlapping ages (10, 12, 14 and 16 years). The subjects were subsequently measured, in 2006, 8 years after the conclusion of the study. All boys reached adult height at the last observation, on average, 21 years of age. Boys 13, 14, 15 and 16 years of age were included in the present analysis $(n=308)$. The population-based sample was stratified by the number of districts in Madeira, educational level and school facilities. The study was approved by the Medical Ethics Committee of the University of Madeira.

\section{Measurements}

Anthropometric dimensions were taken using procedures described by Claessens et al. (1990). Height was measured with a stadiometer and sitting height with a stadiometer mounted on a standardized table. Measurements were made to the nearest millimetre. Triceps and subscapular skinfolds were measured with a Harpenden skinfold caliper to $0.2 \mathrm{~mm}$. Anthropometrists were trained before the study and intra- and inter-observer reliability was verified. In-field reliability was also verified during the course of the study. All estimates were well within ranges of previously reported reliability coefficients and measurement errors (Freitas et al. 2004).

In order to verify possible systematic bias (see statistical analysis) in the prediction of adult height, mean differences between measured and predicted adult stature were verified in 
Table I. Regression coefficients for the prediction of adult height with the Beunen-Malina method (Beunen et al. 1997).

\begin{tabular}{lllllll}
\hline $\begin{array}{l}\text { Age groups } \\
(\text { years })^{\star}\end{array}$ & $\begin{array}{c}\text { Intercept } \\
(\mathrm{cm})\end{array}$ & $\begin{array}{c}\text { Height } \\
(\mathrm{cm})\end{array}$ & $\begin{array}{c}\text { Sitting } \\
\text { height }(\mathrm{cm})\end{array}$ & $\begin{array}{c}\text { Triceps } \\
(\mathrm{mm})\end{array}$ & $\begin{array}{c}\text { Subscapular } \\
(\mathrm{mm})\end{array}$ & $\begin{array}{c}\text { Chronological } \\
\text { age (years) }\end{array}$ \\
\hline 13 & 147.99 & 0.87 & -0.77 & 0.54 & -0.64 & -3.39 \\
14 & 142.65 & 1.03 & -1.04 & 0.76 & -0.92 & -3.24 \\
15 & 153.14 & 1.01 & -0.91 & 0.64 & -0.93 & -4.41 \\
16 & 99.82 & 1.06 & -0.74 & 0.37 & -0.88 & -2.28 \\
\hline
\end{tabular}

*Age groups are defined so that the whole year is the midpoint of the range: $12.50-13.49,13.50-14.49,14.50-15.59$ and 15.50-16.59 years. The age groups are referred to in the text as, respectively, 13, 14, 15 and 16 years.

different maturity groupings at each age level. For this purpose skeletal age (radius-ulna and short bones, RUSage) was assessed using the Tanner-Whitehouse 2 method (Tanner et al. 1983b). Skeletal age (SA) ratings were made by the same trained observer (Freitas et al. 2004). Relative skeletal age $\left(\mathrm{SA}_{\mathrm{rel}}\right)$ was defined as skeletal age (SA) minus chronological age (CA). Positive values indicate skeletal maturity in advance of CA (early), while negative values indicates a lag skeletal maturity relative to CA (late). Three maturity groups were formed on the basis of the SA - CA differences at each age level:

Early: $\mathrm{SA}_{\text {rel }}$ above mean $\mathrm{SA}_{\text {rel }}+1 \mathrm{SD}$

Average: $\mathrm{SA}_{\text {rel }}$ within $\pm 1 \mathrm{SD}$

Late: $\mathrm{SA}_{\text {rel }}$ below mean $\mathrm{SA}_{\text {rel }}-1 \mathrm{SD}$.

\section{Statistical analyses}

As in the original study (Beunen et al. 1997), four age groups (13, 14, 15 and 16 years) were considered. The regression equations and regression coefficients of the original method were used in this sample of Madeira adolescents to predict adult height (Table I). Predicted adult height was correlated with measured adult height. Mean error of prediction and standard deviations were also calculated. In order to verify if the error of prediction varies by maturity level, Pearson correlations between measured and predicted adult heights were calculated for maturity groups within the four CA age groups. Residuals (means and SDs) were also calculated. Mean differences between predicted and measured adult heights for the three maturity groups in each age level were tested for deviation from zero, i.e. no systematic bias. All calculations were made using SAS procedures (SAS Institute Inc., 2004).

\section{Results and discussion}

Correlations between predicted and measured adult heights, the mean difference between the two and the residual standard deviations or standard error of estimate (SEE) are summarized in Table II. Age-specific correlations vary between 0.70 and 0.85 ; the coefficients increase with increasing age as boys gradually approach adult height. The systematic estimation error is $2.3 \mathrm{~cm}$ at 13 years of age but in boys 14-16 years, mean differences vary between $-1.1 \mathrm{~cm}$ and $0.1 \mathrm{~cm}$. SEE varies between 3.3 and $4.7 \mathrm{~cm}$.

There is no evidence for systematic bias in eight of the 12 age-specific maturity groups. In these groups, mean differences between predicted and measured adult heights do not deviate significantly from zero. A significant bias (significantly different from zero) is evident at younger ages, specifically in three of the six age-specific maturity groups. SEEs in the agespecific maturity categories are relatively similar, more so at older ages: $3.5-5.1 \mathrm{~cm}$ at 
Table II. Mean measured and predicted adult heights, correlations, mean differences and standard errors of estimate (SEE) of predicted adult height at specified age levels for this sample, correlations and SEEs in the original Beunen-Malina method (Beunen et al. 1997).

\begin{tabular}{lccccc}
\hline Adult height & $\begin{array}{c}\text { Total } \\
(n=302)\end{array}$ & $\begin{array}{c}13 \text { years } \\
(n=67)\end{array}$ & $\begin{array}{c}14 \text { years } \\
(n=91)\end{array}$ & $\begin{array}{c}15 \text { years } \\
(n=60)\end{array}$ & $\begin{array}{c}16 \text { years } \\
(n=84)\end{array}$ \\
\hline Adult height $(\mathrm{cm})$ & 174.9 & 174.9 & 175.5 & 174.9 & 174.4 \\
Predicted adult height $(\mathrm{cm})$ & 175.0 & 177.2 & 175.6 & 174.1 & 173.3 \\
Correlation & 0.76 & 0.70 & 0.74 & 0.83 & 0.85 \\
Difference $(\mathrm{cm})$ & 0.08 & 2.3 & 0.1 & -0.8 & -1.1 \\
SEE $(\mathrm{cm})$ & 4.2 & 4.7 & 4.3 & 3.3 & 3.7 \\
Correlation Beunen-Malina & & 0.70 & 0.79 & 0.80 & 0.87 \\
SEE Beunen-Malina $(\mathrm{cm})$ & & 4.2 & 3.7 & 3.7 & 3.0 \\
\hline
\end{tabular}

13 years, $2.1-4.4 \mathrm{~cm}$ at 14 years, $3.3-3.5 \mathrm{~cm}$ at 15 years, $3.6-4.6 \mathrm{~cm}$ at 16 years (results not provided, tables can be obtained upon request).

The cross-validation of the Beunen-Malina method to predict adult height was thus verified in a sample of male adolescents living in the islands of Madeira and Porto Santo, Portugal. The method shows fairly good validity. Correlation coefficients between predicted and measured adult heights and SEEs are very similar in the original and cross-validation samples (see Table II). Moreover, SEEs at 13-15 years of age are similar to the original predictions of the Tanner-Whitehouse method using CA, SA and present height as predictors in the regressions. At 16 years the SEE of the Tanner-Whitehouse method is smaller, $2.1 \mathrm{~cm}$, than that in the cross-validation sample using the Beunen-Malina prediction method without skeletal age as a predictor, $3.7 \mathrm{~cm}$ (Tanner et al. 2001). This provides good evidence that the Beunen-Malina method is a valid method to predict adult height in adolescent boys and can be used in European populations or populations from European ancestry.

If adult height can be predicted with a reasonable level of accuracy from anthropometric dimensions (height, sitting height, triceps and subscapular skinfold) and CA at a single observation, percentage of adult height attained at a given age can be derived and used as an estimate of biological maturity status in children and adolescents. The rational for this approach is as follows: two boys of the same age can have the same height, but one is closer to mature height than the other. The individual who is closer to mature height is advanced in maturity status compared to the individual who is more removed from mature height (Malina et al. 2004). Percentage of mature height attained at a given age is positively related to skeletal maturity during childhood (Bayley and Pinneau 1952; Bayley 1962) and to sexual, skeletal and somatic maturity during adolescence (Bielicki et al. 1984; Nicolson and Hanley 1953).

The protocol used in the present study does not require invasive measurements either radiation as in skeletal and dental maturity or invasion of privacy as in assessments of secondary sex characteristics. Adult (mature) height can be predicted from four anthropometric dimensions - height, sitting height, triceps and subscapular skinfold - in addition to CA. The Beunen-Malina method is thus a non-invasive and valid addition to techniques available for the estimation of biological maturity status in adolescent boys.

\section{Acknowledgements}

The Madeira Growth Study was co-sponsored by the POP-RAM II and III, within the scope of the European Social Funds, via CITMA and the Professional Qualification Centre. 


\section{Role of the sponsors}

The role of the sponsors in the different study periods was to approve the project and to provide financial support. They had no role in the design and planning of the study, data collection, statistical analysis, interpretation, review or approval of the manuscript.

\section{Disclosure}

Financial disclosures: none. The contents of this manuscript are the sole responsibility of the authors and do not necessarily reflect the views of the sponsors.

Declaration of interests: The authors report no conflicts of interest. The authors alone are responsible for the content and writing of the paper.

\section{References}

Bayley N. 1962. The accurate prediction of growth and adult height. Mod Probl Paediatr 7:234-255.

Bayley N, Pinneau SR. 1952. Tables for predicting adult height from skeletal age: Revised for use with the GreulichPyle hand standards. J Pediatr 40:423-441.

Beunen G, Malina RM. 2008. Growth and biological maturation: Relevance to athletic performance. In: Hebestreit H, Bar-Or O, editors. The young athlete. Malden, MA: Blackwell Publishing, pp. 3-17.

Beunen G, Malina RM, Lefevre J, Claessens AL, Renson R, Simons J. 1997. Prediction of adult stature and noninvasive assessment of biological maturation. Med Sci Sports Exerc 29:225-230.

Bielicki T, Koniarek J, Malina RM. 1984. Interrelationships among certain measures of growth and maturation rate in boys during adolescence. Ann Hum Biol 11:201-210.

Claessens AL, Vanden Eynde B, Renson R, Van Gerven D. 1990. Tests and measurements. In: Simons J, Beunen GP, Renson R, Claessens ALM, Vanreusel B, Lefevre JAV, editors. Growth and fitness of Flemish girls: The Leuven Growth Study. Champaign, IL: Human Kinetics, pp. 21-39.

Freitas D, Maia J, Beunen G, Lefevre J Claessens A, Marques A, Rodriques A, Silva C, Crespo M, Thomis M, Sousa A, Malina R. 2004. Skeletal maturity and socio-economic status in Portuguese children and youth: The Madeira Growth Study. Ann Hum Biol 31:408-420.

Khamis HJ, Roche AF. 1994. Predicting adult stature without using skeletal age: The Khamis-Roche method. Pediatr 94:504-507.

Malina RM, Bouchard C, Bar-Or O2004. Growth, maturation, and physical activity, 2nd ed. Champaign, IL: Human Kinetics.

Nicolson AB, Hanley C. 1953. Indices of physiological maturity: Derivation and interrelationships. Child Develop 24:3-38.

Roche AF, Tyleshevski F, Rogers E. 1983. Non-invasive measurement of physical maturity in children. Res Quart Sport Exerc 54:364-371.

Roche AF, Wainer H, Thissen D. 1975. The RWT-method for the prediction of adult stature. Pediatr 56: $1026-1033$.

SAS Institute Inc. 2004. SAS/STAT 9.1 user's guide. Cary, NC: SAS Institute.

Tanner JM, Healy MJR, Goldstein H, Cameron N2001. Assessment of skeletal maturity and prediction of adult height (TW3 Method), 3rd ed. London: Saunders.

Tanner JM, Landt KW, Cameron N, Carter BS, Patel J. 1983a. Prediction of adult height from height and bone age in childhood. Arch Dis Child 58:767-776.

Tanner JM, Whitehouse RH, Cameron N, Marshall WA, Healy MJR, Goldstein H1983b. Assessment of skeletal maturity and prediction of adult height, 2nd ed. New York: Academic Press.

Wainer H, Roche AF, Bell S. 1978. Predicting adult stature without skeletal age and without parental data. Pediatrics 61:569-572. 